\title{
Comprehension, Management, and Treatment of Polycystic Ovarian Syndrome via Allopathic, Unani and Ayurvedic Perspectives
}

\author{
Aasiya Bashir ${ }^{1}$, Lahanya Guha ${ }^{2}$ and Ishfaq Ahmad Bhat ${ }^{3 *}$ \\ 1Department of Pharmaceutical Sciences, University of Kashmir, India \\ 2Department of Pharmacology and Toxicology, National Institute of Pharmaceutical Education and Research, S.A.S. Nagar (Mohali), India
}

3Northern Railway Hospital, Associated Sri Mata Vaishno-Devi Narayana Super specialty Hospital(SVDNSH), India

Submission: January 25, 2021; Published: March 03, 2021

*Corresponding author: Ishfaq Ahmad Bhat, Northern Railway Hospital, Associated Sri Mata Vaishno-Devi Narayana Super specialty Hospital(SVDNSH), India

\section{Abstract}

Objective: The present review work is designed to gather knowledge about polycystic ovarian syndrome (PCOS) to manage and treat this endocrine disorder through three different perspectives viz, Allopathic, Unani and Ayurvedic studies from the absolute beginning of its onset among women of reproductive age group.

Background: Polycystic ovary syndrome (PCOS) is one of the most common endocrine disorders, affecting 2.2 to $22.5 \%$ of women in the reproductive age. As time elapses prevalence of PCOS is increasing world-wide. This could have a disastrous outcome on health since it is linked with multiple noxious comorbidities. Hence management or treatment should be done at the earliest without any unnecessary delay as it can end up in social stigma.

Result: Management and treatment of Polycystic ovary syndrome via either of Allopathic, Unani or Ayurvedic systems show a good outcome, for it addresses multiple issues linked to the said disorder whether of genetic or metabolic background. Disorders like hyperandrogenism, anovulation, insulin resistance or hyperinsulinemia, and polycystic ovarian morphologic features in adolescent and adult females are all intervened properly.

Conclusion: The majority of women are ignorant of this pathological condition and even the health care professionals are not much familiarized with these comorbidities linked with the condition. The majority of people lack behind in the treatment with the allopathic system because of its tremendous adverse effects, so here based on patients' choice and will, the patient can opt for Unani or ayurvedic system instead, with least or nil side effects and with complete fruitful outcomes.

keywords: PCOS; Allopathy; Unani; Ayurveda; Management; Treatment

Abbreviations: AMH: Anti-Mullerian Hormone; BPA: Bisphenol A; BMI: Basal Metabolic Index; CVD: Cardiovascular Disease; CC: Clomiphene Citrate; EDC's: Endocrine Disruptor Chemicals; FSH: Follicle-Stimulating Hormone; FAI: Free Androgen Index; FMR1: Fragile X Mental Retardation 1; HCG: Human Chorionic Gonadotropin; IGFBP-1: Insulin-Like Growth Factor-Binding Protein 1 (IBP-1); LH: Luteinizing Hormone; OC's: Oral Contraceptives; OHSS: Ovarian Hyperstimulation Syndrome; PCOS: Polycystic Ovarian Syndrome; PCOM: Polycystic Ovarian Morphology; SHBG: Sex Hormone-Binding Globulin; USG: Ultrasonography

\section{Introduction}

Polycystic ovarian syndrome (PCOS), or hyperandrogenic anovulation (HA) [1] American gynecologists Irving F. Stein and Sr Michael L Leventhal, named it stein Leventhal syndrome [2] and is most mentioned endocrinopathies among women of childbearing age with a prevalence of $9.13 \%$ in Indian population [3]. It's been documented that it is not only metabolic disorder but has genetic origin either, otherwise in before time it was mostly claimed to be a metabolic pathological case as being reversible in nature [46]. The first time in 1935, American gynecologists Irving F. Stein, Sr. and Michael L. Leventhal, documented this endocrine feminine disorder, which gave it another name as Stein-Leventhal syndrome $[7,8]$. Also, this PCOS was documented in 1721 in Italy, concerning Cyst- changes in ovaries were mentioned in 1844(Norman, Robert, 
Gabor Kovac, 2013). PCOS symptoms appear in near about5\% to $10 \%$ of women of childbearing age (around 12 to 45 old women) [9]. PCOS is the primary culprit for women subfertility [10-12] and claims to be disastrous endocrinopathy in the female population [13]. Commonly a USG scan of ovaries shows a multitude of cysts present, though not encountered in every case. PCOS is a cluster of symptoms with hyperandrogenism as one of the main symptoms. In such instances, it presents with symptoms like acne vulgaris or pimples, alopecia or hair fall, abnormal menstrual cycle (irregular or absent periods), polycystic ovaries (a string of small beads pattern cysts containing small collections of fluid in ovaries, actually representing ova arrested during their growth, infertility or failure to conceive, hirsutism or unwanted facial hair growth or body, etc $[13,14]$.

PCOS patients may not share all of their symptoms and the manifestation may change and get worse with time if the woman turns obese. PCOS is thought to be a hereditary disorder, the outcome of genetic variations resulting in a complex genetic characteristic. It can run in families, thus may have polycystic ovary with no apparent symptoms. Insulin plasma levels go up because of its effectiveness in the target tissues [13]. This surplus insulin can affect the ovaries by raising androgen (male hormone) production, which can result in masculinization, such as male pattern hair growth or loss with acne vulgaris in women in addition to interference with ovulation. Insulin resistance as the underlying cause of PCOS has given birth to a new debate among clinicians and the scientific community globally and has paved the way for use of insulin sensitizers like metformin or gloxazones in its treatment [15]. Research has also revealed that women with PCOS suffer low-grade inflammation and insulin resistance and it seems to link it with other lifestyle disorders like diabetes mellitus, coronary heart disease, metabolic syndrome, and others. Infertility, one of the manifestations of PCOS being greatly excluded, is very common and requires particular attention [16]. Since the etiology (causation) of PCOS is unclear, the treatment by and large remains to be empirical. Currently, lifestyle management is the most important strategy in addition to some limited medications (insulin sensitizers and anti-androgens). The increase in reproductive disorders like PCOS and infertility has been linked to a sedentary lifestyle and environmental exposure to harmful agents like endocrine disruptor chemicals (EDC's) including pesticides, plasticizers like bisphenol A (BPA) etc. Hence, we need to be aware of and understand the risk factors resulting in adverse health effects [17]. It is tough luck that the women with PCOS are being treated with cosmetic measures which include laser hair removal, plucking, trimming, waxing, or bleaching, skin creams, etc.) for dermatological symptoms or by oral contraceptive pills for the reasons of menstrual irregularity. Therefore, for most women, it works for their issues with skin or making their periods regular without fixing the underlying problem only provides psychological satisfaction which has been reported in such patients allocated for laser-assisted hairremoval
[18]. The rise of PCOS among young girls is alarmingly high. Every other girl is complaining about irregular periods, acne, or excessive hair growth. PCOS leads to extreme stress levels among teenage girls and even after marriage. PCOS is relatively misunderstood globally thus spreading awareness seems to be imperative. There is a need for increased awareness, early recognition of symptoms, and a multidisciplinary approach for diagnosis of PCOS.

To address and assess this morbid endocrinopathy, it is the responsibility of health care providers to educate the individuals, so that the population will be well acquainted with the knowledge of its symptoms and it would become easy for the patient to report this issue at earliest. As it is the most neglected syndrome and female folk needs to know the value of presentation and consequences of the disorder and thus has become a necessity, so PCOS deserves attention [19].

\section{Epidemiology}

The World Health Organization accounts that it impacts 116 million female folk worldwide as of 2010 (3.4\% of women) [20]. One community-based prevalence study using the Rotterdam criteria found that about $18 \%$ of women had PCOS and that $70 \%$ of them were previously undiagnosed [13]. Ultrasonographic findings of polycystic ovaries are found in $8-25 \%$ of normal women. $2114 \%$ women on oral contraceptives are found to have polycystic ovaries [21].

\section{Etiology}

As in ovarian USG scan the morphology sounds like a multitude of cysts scattered in the ovary, so got the name as PCOS, actually which are immature follicles instead. The primordial follicles give rise to these follicles, no development takes place as it is inhibited at the beginning of an antral stage because of the abnormal PCOS Ovarian physiology. The follicles are visible along the ovarian periphery and seems a 'necklace' on a USG scan. PCOS women experience a high frequency of hypothalamic GnRH pulses, which causes an increase in the LH/FSH ratio [22]. various PCOS Patients suffer insulin resistance and are mostly fat. Raised insulin value becomes the main culprit in disturbance in the hypothalamicpituitary-ovarian axis resulting in this syndrome. Elevated insulin elevates GnRH pulse frequency, LH over FSH subjugation, raised androgen production by PCOS ovaries, [23] cuts down follicular maturation, and counters SHBG binding, encouraging PCOS. Insulin resistance has been a similitude in both healthy weight and obese PCOS Patient [23]. In a female group having high levels of fat deposit, have elevated value of male hormone androgens which contributes to the development of excess hair on the body, similar to male (hirsutism and virilization) and female hormone estrogen values are elevated thus by negative feedback inhibits FSH [24]. As mentioned above, this syndrome is linked with chronic inflammatory conditions, anovulation is linked with various PCOS symptoms and associated with these inflammatory mediators [25]. There appears a strong link between raised levels 
of oxidative stress and this endocrinopathy [26]. It is documented and claimed that hyperandrogenemia in patients with PCOS is because of a decline in the serum level of IGFBP-1, which brings about an elevation in the value range of free IGF-I, stimulating the ovary to produce androgen, the new survey declares this process to be not so [27]. This syndrome is linked to a particular FMR1 sub-genotype. The study reveals that those females possessing heterozygous-normal/low FMR1 have multiple cysts like characteristics of rapid follicle-action and highly energetic ovarian function [28].

\section{Diagnostic criteria}

History inquiry of monthly cycles, male pattern hair growth, gain in body mass, and suppressed or breast regression. As these basic questions are done and proven clinically help in diagnosing this syndrome near about $77.1 \%$ (95\% confidence interval [CI] $62.7 \%-88.0 \%)$ and a specificity of $93.8 \%(95 \% \mathrm{CI}$ $82.8 \%-98.7 \%$ ) [29]. USG Scan, particularly to ascertain multiple cysts morphology. It is thought to be because of abnormal or anovulatory ovary, manifesting oligomenorrhea, amenorrhea, or even polymenorrhea. Normally in the monthly cycles, an ovum is released after the rupture of the dominant follicle. This cycle continues it begins to produce corpus luteum, ovulation decline after a period of 14 days. Patients suffering from PCOS encounter "follicular arrest"; i.e., many ovarian follicles grow only to a specific confined measure of $5-7 \mathrm{~mm}$, thus hampering these follicles to reach $16 \mathrm{~mm}$ thus suspending the preovulatory phase. As per Rotterdam criteria, on USG scan 12 or more small follicle visibility is required to declare the same [8] New research reveals the number of 25 ovarian follicles to declare the presence of this very syndrome in such females of reproductive age group [30]. In case a high-resolution transvaginal ultrasonography machine is unavailable, a minimum of $10 \mathrm{ml}$ ovarian volume is said to be approved criteria for having polycystic ovarian morphology [30]. Measure of androgens, androstenedione, and testosterone are claimed to be elevated [13].

\section{Management}

After compiling and merging all the three systems of medicine following suggestions should be followed upon. Management goes as per the symptoms and signs, that a patient manifests, for instance, anovulation or other cyclic abnormality, hyperandrogenism leading to infertility.

\section{Body mass management}

Proof of this fact is that excessive male hormone leads to central obesity featured by waist/hip ratio independent of the body mass index (BMI). It is a fact that this syndrome is linked with anovulation, long conceiving time, miscarriages, etc.(such as pre-eclampsia and gestational diabetes). High body mass index among 35\%-60\% of female PCOS patients is associated with drug insensitivity for many drugs some of which include, clomiphene citrate (CC), gonadotropins, and even diathermy via laparoscopy.
Losing weight modifies hormonal function and elevates the chances of ovulatory menses which favors the chances of becoming pregnant. Correction of menses and ovulation is sure with loss of body weight as less as $5 \%$ of the initial weight. It can modify circulating androgen and glucose values and but, countering the weight serves no specific purpose other than in obese ones with a BMI $>25-27 \mathrm{~kg} / \mathrm{m}^{2}$ [ 7]. To assess this problem, a clinician needs to promote a refined lifestyle (feeds and exercise) medical treatment as well [31] and should be done during the preconception phase. eatables best suggested for overweight PCOS female folk should be calory poor, or limiting carbohydrate consumption, as it claims to bring about $5 \%-10 \%$ decline which suffices to resume ovarian physiology in affected patients [7].

\section{Exercise}

Many researchers conducted to manifest the impact of exercise on the correction of this syndrome. No special results were obtained when different foods, were compared, but a longer weight loss time serves a useful purpose, hence enormous exercise is suggested for such individuals. It becomes slightly hectic in terms of type, duration, and frequency of exercise [32].

\section{Diet and Exercise}

Many of the symptoms of PCOS can be relieved through weight management, dietary changes, and exercise. A study in Australia noted that lifestyle changes with diet, exercise, help alleviate symptoms associated with PCOS [31]. Weight loss through diet, exercise, and lifestyle reduce 6 androgens circulating in the body, and insulin sensitivity improves as well as a reduction in hyperinsulinemia and improved menses cycle and fertility. A low glycemic index diet can help to normalize hormone levels within the body [32]. This is indicated because highly refined foods increase blood sugar levels and lead to an increase in inflammation and tissue damage in the body. Including foods such as fresh vegetables, fruits, and proteins help to stabilize hormones. More specifically the inclusion of cruciferous vegetables like kale, broccoli, cabbage, collard, and mustard greens has shown their ability to reduce estrogen levels [33].

\section{Lifestyle Treatments}

Sweating and aerobic exercise is a prescribed treatment because of its ability to detoxify the body and increasing endorphins which decreases stress and cellular inflammation [34]. To help reestablish ovulatory flow such protocols as going on regular walks in nature, waking at the same time, sleeping in darkness, turning off electronic devices by ten o'clock, and eating the largest meal of the day at noon has been recommended by Dr. Lipman, an integrative medicine specialist in New York [35]. Additionally, stress reduction alleviates many symptoms of PCOS. Meditation practiced between 15-20 minutes twice a day has been suggested by Director Emeritus of the Benson-Henry Institute (BHI), and Mind-Body Medicine, Herbert Benson Professor of Medicine at Harvard Medical School [31]. Punctual Exercise is 
tremendously effective in countering imbalance in the normal functioning as of lifestyle problems as PCOS.

\section{Bariatric surgery}

It has a new instrument in countering bodyweight particularly in the far obese individuals. Besides, if diet and exercise do not provide a benefit of desire, bariatric surgery is the best choice. A comprehensive search of the electronic database was done. Metaanalysis was done on PCOS, excessive hair growth, and abnormal cycles, supporting bariatric surgery as the best alternative. Thirteen primary studies where 2130 patients with PCOS were ascertained. Before surgery incidence of PCOS was $45.6 \%$ which ultimately decreased to $6.8 \%$ and other benefits were ascertained as well [36].

\section{Allopathic Treatment}

Currently, the most preferred and better serving regimen of PCOS is opting for allopathic medicines like Clomiphene citrate, Metformin, Tamoxifen, and Troglitazone.

\section{Clomiphene citrate (CC)}

It comprises a first-line regimen for inducing ovulatory cycles in individuals with PCOS, imposing fewer adverse effects with cost effective advantage. CC being an estrogen receptor antagonist have a direct effect on negative feedback of the estrogen-signaling pathway, thus elevates FSH. It is a non-steroidal fertility drug. It is witnessed to be efficacious in high doses of $150 \mathrm{mg}-200 \mathrm{mg}$ for ovulation induction in those women who would not conceive with low dosage regimens [37].

Legro et al witnessed notable deviations in conceiving rates among individuals with a BMI $>30$ against having a BMI $<30$ individuals. They were provided with Doses of 50-150mg for 5 days, starting on days 3 or 5 of a progestin-induced spontaneous cycle. CC witnessed ovulatory cycles in $75 \%-80 \%$ of PCOS patients, gestation rate was assessed, it was approximately $22 \%$ per ovulation cycle $[38,39]$. The observation documented that clomiphene resulted in a twin pregnancy and single pregnancy was witnessed with single uses of tamoxifen and letrozole separately. Clomophene misscarriages $10(20 \%)$, With tamoxifen $3(6 \%)$ and Letrozole $4(8 \%)$ live birth rate: group A:22(44\%) Group B:17(34\%) Group C:21(42\%) [40,41].

\section{Human menopausal gonadotropin (hMG), Human chorionic gonadotropin (hCG), and Dexamethasone combinations}

A clinical study in which the administration of above three compounds to 27 infertile females with this syndrome who couldn't become pregnant after taking clomiphene citrate and hMG-hCG alone. In total 22 (81\%) of females begin with ovulatory cycles as per their basal body temperature and progesterone range, and $20(74 \%)$ expected a child while 15(74\%) conceived females concluded by giving live births (14 singletons and 1 set of twins), and 5 (25\%) ended in miscarriage during firstthree months. One of the subsequent regimens was delicate by medium hyperstimulation of ovaries. For stimulating ovulation, the average hMG dose used was noticeably lowered from the range of 25 ampules with hMG-hCG alone to 18 ampules under the amalgamated regimen $(\mathrm{P}<0.01)$. Amalgamation of hMG-hCG and dexamethasone is an extra, safe, and proves to be an efficient regimen for patients with thies syndrome who otherwise do not respond to [42].

\section{Insulin sensitizers}

The research is so far confined. rosiglitazone and pioglitazone have less short-term risk, teratogenicity is not studied so far (pregnancy category C of the US FDA guidelines). Withdrawal of drugs is mandatory as the patient's baby is due in months. There is Impaired insulin signaling via protein kinase A (Akt) and Akt substrate (AS160) in part. At the genetic/ molecular level, there is a loss of insulin sensitivity in the skeletal muscle of PCOS women. Pioglitazone overcomes this problem by improving signaling through Akt andAS160, thus enhances insulin sensitivity [43].

Medication with metformin is linked with elevated menstrual periodicity, cycles are ovulatory, and a decline in circulating androgen measures. Cochrane review was modified by Tang et al regarding insulin-sensitizing drugs (metformin, rosiglitazone, pioglitazone, Dchiro -inositol) PCOS suffering patients, with symptoms of amenorrhea, oligomenorrhea and subfertility declared that metformin proves useful in child conceiving and causes ovulatory cycles. But, there was NO proof about the same drug in contributing towards the live birth rates when taken as a single drug or in amalgamation with clomiphene. hence, treatment with this drug manifests no solid prove in contributing reproductive function in patients with PCOS [44].

\section{Anastrozole and letrozole}

These are selective aromatase inhibitors, highly effective as ovulation-inducing drugs. Their action appears to be potent and reversible, unlike CC, having a half-life of 5-7 days. Vast research is done on letrozole than anastrozole. It was acquainted as a supportive reproduction treatment linked with various adverse effects of CC, CC's low efficacy, and the intricacy of gonadotropin regimen. Letrozole is witnessed to be responsible for live births in PCOS patients [45]. The function of Letrozole is inhibition of estrogen production in the hypothalamus-pituitary axis, where an elevation in gonadotropin-releasing hormone ( $\mathrm{GnRH}$ ) and FSH occurs. It is claimed that there is a decline in aromatase in patients suffering from PCOS, thus lowers the follicle formation meant for ovulatory cycles [45].

\section{Glucocorticoids}

Prednisone and dexamethasone stimulate ovulation. Elnashar et al declared that the addition of dexamethasone (high dose, short course) to CC in CC-resistant PCOS with normal DHEAS stimulates ovulation and is linked with zero unwanted antiestrogenic 
effect on the endometrium and frequency of conception shows an increase in a noticeable bulk of PCOS patients [46]. For such individuals with elevated adrenal androgen, administration of low-dose dexamethasone $(0.25-0.5 \mathrm{mg})$ at bedtime is of benefit. In a research carried over 230 PCOS individuals didn't ovulate after administering $200 \mathrm{mg}$ of CC for 5 days, later extra $2 \mathrm{mg}$ of dexamethasone was given from days 5-14 and it was observed that there occurred an increase in ovulation rate and thus raised the overall conception rate due to their ability of unwanted effects on insulin sensitivity; so, not used much [46]. These allopathic drugs have many unwanted negative effects like arthritis, joint or muscle pain, feverish and psychological unwanted effects like getting irritated, changes in mood, anxiety, and dissertation. Hence to counter this, other optional regimens should be available with the least adverse effects is required.

\section{Unani Perspective}

This regimen is a pretty old plant-derived and drugs from animals and mineral sources are included either. It witnesses the cure of a multitude of diseases of humans. The reasons for subfertility in obese females and PCOS as mentioned in the allopathic system are alike in terms of etiology and features of our in Unani medicine, except the cellular and hormonal concept. The drugs for database tams, or and sue megabrand are mostly beneficial in treating this syndrome, but proof of its efficacy is awaited so far.

\section{Unani treatment}

This regimen is a far old plant-derived and drugs from animals and mineral sources are included either. It witnesses the cure of a multitude of diseases of humans. The reasons for subfertility in obese females and PCOS as mentioned in the allopathic system are alike in terms of etiology and features of our in Unani medicine, except the cellular and hormonal concept. The drugs for database tams, or and sue mizajbarid are mostly beneficial in treating this syndrome, but proof of its efficacy is awaited so far. Health care professionals in this system made a mention of a multitude of diseases, which include Qillat e Tams, Ihtibaz e Tams, Uqr. Hence understanding management of the Unani system of medicine towards Uqr due to abnormally high body mass and this syndrome doesn't show any similarity with Modern science. The Unani treatment is known as IlajbilZid, meaning the medicine which has the opposite Mizaj (Temperament) of the selected impacted akhlat and the affected individuals treated with it [31].

Ghir e tabayeemada (Abnormal humors) such as Ghir e tabayeeBalghamvoSawda, consumption of Unani Joshanda( Decoction)possessing function of Munzij e Brigham for Ghir e TabayeeBalgham and the Munzij e Sawada for Ghir e TabayeeSawda is given in the dose of half a cup morning and the evening for about fortnight. In case the Ghir e Tabayee Sawda is Ghaleez in Khiwam then munzij becomes the drug of choice. In this case, dawa must also have good activity of Mudir - e Haiz(Emmenogogue) and Muqawwi e A'za e Rayeesa (General tonic for vital organs) (ArRazi,
1961) [31,47]. Many scientific studies have proven the effect of following Unani drugs: Aelva(Aloe barbadensis) [48], Sarphunka (Tephrosiapurpurea) [49], Lajvanti (Mimosa pudica) [50] On PCOS. Ashwagandha(WithaniasomniferaDunal.) and Kharekhask (Tribulus Terrestris Linn.) are drugs of choice in Unani medicine. Multitude of researches are done on these drugs and reported for Asgard to possess 40 anxiolytics, antioxidant, anti-carcinogenic, anti-aging, cardioprotective, hypothyroid, immunomodulatory, antibiotics like antifungal, antibacterial, hypocholesterolemic, hypocholesterolemic and CNS related activities [51]. Kharekh ask possesses antiurolithiatic, aphrodisiac, CNS stimulatory, and cardiotonic activities [52]. Five common medicines aid in the treatment of PCOS.

Satawar (Asparagus racemosus): Satawar helps promote the normal growth of ovarian follicles, modifies the monthly cycles, and provides nourishment to female reproductive health. Satawar aids in assessing the hyperinsulinemia as for its natural plant-based estrogen) [53].

Giloe (Tinospora Cordifolia): It is a strong herb acting against inflammatory conditions. Chronic inflammation in tissues is believed to be a cornerstone of insulin imbalance and multiple cysts in the ovary. It affords nourishment of the body tissues and boosts metabolism spontaneously. It also aids in minimizing insulin resistance [54].

Saunf (Foeniculum vulgare): There are specific active constituents in fennel, that aids in lowering insulin resistance and in countering inflammation in such a syndrome. These phytoconstituents of fennel declines the cellular imbalance that was otherwise bringing about metabolic imbalance in this syndrome [55].

Triphala: amalgamation of trio Amla (Emblica Officinalis), Halela (Terminalia chebula), and Balela (Terminalia bellerica) mixed in it. Possesses a high range of vitamin C- a very potent natural antioxidant countering inflammation by scavenging free radicals. Triphala acts as a cleansing and detoxifying agent [56].

Aelva (Aloe barbadensis): It corrects menstrual cycle periodicity and modifies normal menstruation and corrects ovarian hormonal disturbance [56-68].

\section{Ayurvedic Management Of PCOS}

Ayurveda is an all-encompassing recuperating framework created in India over 3,000 years back [69]. One of the world's most established all-encompassing practices, it depends on the idea that wellbeing is accomplished through a harmony between your psyche, body, and soul $[69,70]$.

\section{Ayurvedic Treatment of Polycystic Ovarian Syndrome}

Ayurveda put forward various specific and individualized treatments that aid in alleviating and eliminating the symptoms of PCOS. Ayurveda treats disease via diet, herbal medication, and lifestyle changes. Treatments for the disease are indicated based 
upon the nature, size, and etiology of the symptoms. Ayurveda describes PCOS mainly involvement of the doshadhatus and up dhatu, it doesn't correlate the condition of a single disease but the symptoms resemble the features of yonivyapad (arajaska, lohitakshayavandhyapuspaghni and jatiharini ) [31].

Tridosha for PCOS: Ayurveda Practices tridosha i.e.,vatta, pitta Kapha theory for addressing issues of tridosha and other concerned body constituents. Vata vitiation results in irregular menstruation and pain. Herbs such as Shatavari and satapushpa are helpful with these conditions. In the Ayurveda system of medicine, Satapushpa Shatavari powder (SSP) with or without Satapushpa - ShatavariGrita (SSG) Matravasti (therapeutic enema) is more often used for the treatment of menstrual disturbances due to polycystic ovary syndrome (PCOS) (TewariPv, 2008). SHATAVARI aids in the correction of hormonal influence and helps in follicular maturity. Shatapushpa also helps in follicular maturity and acts as an analgesic as well.it counters menstrual irregularity [56]. Pitta vitiation can result in hirsutism, acne, cardiovascular and heart problems. Herbs such as manjistha [57,58] and Ashoka [58] are helpful herbs in treating hirsutism as well as neem and kutki in the treatment of acne [59]. Kapha vitiation results in weight gain, the growth of cysts, and depression. For treating obesity, enema or Bastis prepared with Triphala are suggestive [60]. Triphala and Chandra Prabha are effective obstruction clearing herbs which can clear the presence of cysts [56]. Treating and managing depression in PCOS is a matter of concern, the "standard of life in women with PCOS has been reported lower than of normal women i.e., without PCOS history and even lower than of people with some diseases such as diabetes, asthma, and epilepsy." Depression is treated by doing exercises like the best one called Yoga [61] and the use of herbal drugs like Shatavari, Chandra Prabha, shatapushpa, manjistha, and guggul for Kapha treatment [62].

Panch Karma for PCOS: Pancha Karma is a Fundamental technique in Ayurveda and is very often used in treating PCOS. Pancha Karma consists of five therapies which help to clear ama and balance agni [63]. Panchkarma includes: Vamana, which results in emesis. It is suggested in the treatment of weight loss as it assists in the removal of excess Kaphadosha [64]. Virechana or purgation therapy alleviates pitta by removing heat in the small intestine and liver, which aids in balancing hormonal levels in the body [65]. Basti, or enema, this is one of the kind in Pancha Karma treatment. Both Uttara and rectal Bastis are effective in treating disease in the vagina and uterus. "In diseases of the urinary bladder and vagina and uterus in women [66]. Bastis addresses amenorrhea and hypomenorrhea by cleansing obstructions and restoring flow to Apana Vayu and assists with the elimination of "cumulative impurity stationed all over the body." Once a Basti is given to a patient the medicine runs throughout the body and eases the elimination of excess dosha. Basti regulates the functioning of the hypothalamus which normalizes menstruation [67]. Oleation and fomentation ease the cleaning and purification of the body. "Unction vanishes Vata softens the body and eases exiting retention of excrements. Fomentation (applied) to the functioned patient decreases the viscosity of the impurity obscured in mini channels." Oleating the body internally with ghee and externally with oil softens ama and toxins in the body [68].

Aartava-kshaya: Aartava-kshaya, can be correlated with PCOS has been described as deficiency or loss of artava, artava dose not appears in time or is delayed, is scanty and dose not last for three days. Pain in vagina also can be seen. According to Ayurveda, Aartava-kshaya is a disorder involving Pitta and Kapha doshas, Medas, Ambu/Rasa, Shukra/Artava Dhatu and Rasa, Rakta, Artava Vaha Srotas [71] Therefore Poly Cystic Ovarian Syndrome can also be described with same involvement of Dosha, Dhatu and Upadhatu Kapha predominance manifests as increased weight, subfertility, hirsutium, diabetic tendencies and coldness. Pitta predominance manifests as hair loss, acne, painful menses, clots and heart problems. Vata predominance manifests with painful menses, scanty or less menstrual blood and severe menstrual irregularity [71-73]. The pathology is an obstruction in the pelvic cavity (Apana Kshetra) causing disorders in the flow of Vata. This in turn leads to an accumulation of Kapha and Pitta. The treatment principle is to clear obstruction in the pelvis, normalize metabolism and regulate the menstrual system (Aartava Dhatu). Kapha reducing, insulin enhancing, and hormone rebalancing drugs help to the relieve symptoms of Poly Cystic Ovarian Syndrome.

\section{Conclusion and Future Perspective}

All three systems of medicine contribute to the prevention, mitigation, palliation, and treatment of PCOS effectively. Unani and Ayurvedic treatment show the good result with least or nil side effects in comparison to allopathic systems of medicine, as the latter leaves some side effects behind which is a matter of concern. With the implementation of any one of the above therapies, a woman will see an improvement in many if not in all of her symptoms. Although the treatment varies in all of the three systems of medicine, yet the Management is almost alike in each case showing wonderful results when acted upon. Any of the regimen, of the three therapies, can be opted for depending upon the choice of a patient. Allopathic treatment manifests quick responses, while the Ayurvedic and Unani systems of medicine show slow response in the treatment of PCOS. These treatment systems overall show fewer side effects and have low toxicity thus making them a good candidate for treatment of PCOS and they hold a great potential in future.

\section{References}

1. Kollmann M, Martins WP, Raine-Fenning N (2014) Terms and thresholds for the ultrasound evaluation of the ovaries in women with hyperandrogenic anovulation. Hum Reprod Update 20(3): 463-464.

2. Azziz R, Carmina E, Chen Z, Dunaif A, Laven JSE, et al. (2016) Polycystic ovary syndrome. Nat Rev Dis Primer 2: 1607.

3. Nidhi R, Venkatram P, Raghuram N, Amritanshu R, et al. (2011) Prevalence of polycystic ovarian syndrome in Indian adolescents. J Pediatr Adolesc Gynecol 24(4): 223-227. 
4. Franks S (1995) Polycystic ovary syndrome. N Engl J Med 333(13): 853-861.

5. Legro RS, Strauss JF (2002) Molecular progress in infertility: polycystic ovary syndrome. Fertil Steril 78(3): 569-576.

6. Diamanti-Kandarakis E, Kandarakis H, Legro RS (2006) The role of genes and environment in the etiology of PCOS. Endocrine 30(1): 1926.

7. Mirza S, Naaz S, Alim S (2016) Management of polycystic ovarian syndrome (Keesa-e-. Khusyatur Rehm): Unani perspective. Am J Pharm Health Res 4(1): 24-45.

8. Nabag WO, Farajalla EA, El Sheikh MA (2014) Insulin resistance in infertile Sudanese patients with poly cystic ovarian syndrome (PCOS) at laparoscopy. Journal of Advances in Medicine and Medical Research 4(3): 889-897.

9. Solomon CG (1999) The epidemiology of polycystic ovary syndrome. Prevalence and associated disease risks. Endocrinol Metab Clin North Am 28(2): 247-263.

10. Goldenberg N, Glueck C (2008) Medical therapy in women with polycystic ovarian syndrome before and during pregnancy and lactation. Minerva ginecologica 60(1): 63-75.

11. Boomsma CM, Fauser BC, Macklon NS (2008) Pregnancy complications in women with polycystic ovary syndrome. Semin Reprod Med 26(1): 72-84.

12. Azziz R, Woods KS, Reyna R, Timothy JK, Knochenhauer ES, et al. (2004) The prevalence and features of the polycystic ovary syndrome in an unselected population. J Clin Endocrinol Metab 89(6): 2745-2749.

13. Teede H, Deeks A, Moran L (2010) Polycystic ovary syndrome: a complex condition with psychological, reproductive and metabolic manifestations that impacts on health across the lifespan. BMC Med 8(1): 41.

14. Cortet-Rudelli C, Dewailly D (2006) Diagnosis of Hyperandrogenism in Female Adolescents. Hyperandrogenism in Adolescent Girls. Armenian Health Network Health p. 11-21.

15. Sangeeta S (2012) Metformin and pioglitazone in polycystic ovarian syndrome: a comparative study. J Obstet Gynaecol India 62(5): 551 556

16. Ruan X, Dai Y (2009) Study on chronic low-grade inflammation and influential factors of polycystic ovary syndrome. Med Princ Pract 18(2): 118-122.

17. Rutkowska A, Rachoń D (2014) Bisphenol A (BPA) and its potential role in the pathogenesis of the polycystic ovary syndrome (PCOS). Gynecol Endocrinol 30(4): 260-265.

18. Lee CM (2018) Laser-assisted hair removal for facial hirsutism in women: A review of evidence. J Cosmet Laser Ther 20(3): 140-144.

19. Tang T, Glanville J, Orsi N, Barth JH, Balen AH, et al. (2006) The use of metformin for women with PCOS undergoing IVF treatment. Hum Reprod 21(6): 1416-1425.

20. Vos T, Flaxman AD, Naghavi M, Lozano R, Michaud C, et al. (2012) Years lived with disability (YLDs) for 1160 sequelae of 289 diseases and injuries 1990-2010: a systematic analysis for the Global Burden of Disease Study 2010. Lancet 380(9859): 2163-2196.

21. Strauss JF (2003) Some new thoughts on the pathophysiology and genetics of polycystic ovary syndrome. Ann N Y Acad Sci 997(1): 42-48.
22. Kitzinger C, Willmott J (2002) The thief of womanhood': women's experience of polycystic ovarian syndrome. Social science \& medicine 54(3): 349-361.

23. Kumar V, Cotran RS (1994) Robbins' basic pathology. Archives of pathology and laboratory medicine 118(2): 203.

24. Fukuoka M, Yasuda K, Fujiwara H, Kanzaki H, Mori T, et al. (1992) Interactions between interferon $\gamma$, tumour necrosis factor $\alpha$, and interleukin-1 in modulating progesterone and oestradiol production by human luteinized granulosa cells in culture. Hum Reprod 7(10): 1361-1364.

25. Murri M, Luque-Ramírez M, María Insenser M, Ojeda-Ojeda M, EscobarMorreale HF, et al. (2013) Circulating markers of oxidative stress and polycystic ovary syndrome (PCOS): a systematic review and metaanalysis. Hum Reprod Update 19(3): 268-288.

26. Kelly C, Stenton S, Lashen H (2011) Insulin-like growth factor binding protein-1 in PCOS: a systematic review and meta-analysis. Hum Reprod Update 17(1): 4-16.

27. Gleicher N, Weghofer A, Lee IH, Barad DH (2010) FMR1 genotype with autoimmunity-associated polycystic ovary-like phenotype and decreased pregnancy chance. PloS one 5(12): e15303.

28. Pedersen SD, Brar S, Faris P, Corenblum B (2007) Polycystic ovary syndrome: validated questionnaire for use in diagnosis. Canadian Family Physician 53(6): 1041-1047.

29. Dewailly D, Lujan ME, Carmina E, Cedars MI, Laven J, et al. (2014) Definition and significance of polycystic ovarian morphology: a task force report from the Androgen Excess and Polycystic Ovary Syndrome Society. Human reproduction update 20(3): 334-352.

30. Faslul Haq M (2012) Role of various treatment methods of Ilaj Bit Tadabeer (Regimental therapy) in the management of PCOS.

31. Harrison CL (2011) Exercise therapy in polycystic ovary syndrome: a systematic review. Hum Reprod Update 17(2): 171-183.

32. Marsh K, Brand-Miller J (2005) The optimal diet for women with polycystic ovary syndrome? Br J Nutr 94(2): 154-165.

33. Redman LM, Elkind-Hirsch K, Ravussin E (2011) Aerobic exercise in women with polycystic ovary syndrome improves ovarian morphology independent of changes in body composition. Fertil Steril 95(8): 26962699.

34. Badawy A, Elnashar A (2011) Treatment options for polycystic ovary syndrome. Int J Womens Health 3: 25-35.

35. Skubleny D, Noah JS, Richdeep SG, Mark D, Xinzhe S, et al. (2016) The impact of bariatric surgery on polycystic ovary syndrome: a systematic review and meta-analysis. Obesity surgery 26(1): 169-176.

36. Gorlitsky GA, Kase NG, Speroff L (1978) Ovulation and pregnancy rates with clomiphene citrate. Obstet Gynecol 51(3): 265-269.

37. Legro RS, Huiman XB, William DS, Bruce RC, Michael PD, et al. (2007) Clomiphene, metformin, or both for infertility in the polycystic ovary syndrome. N Engl J Med 356(6): 551-566.

38. Ghafourzadeh M, Mojgan K, Mohammad AK, Mahshid B, et al. (2004) Comparison between two methods of ovulation induction: Clomiphene alone and clomiphene+ tamoxifen in PCOS patients. International Journal of Reproductive Bio Medicine 2(2): 74-77.

39. Sharma S, Geetha R, Gunja B, Indranil S, Sikha B, et al. (2018) Tamoxifen is better than low-dose clomiphene or gonadotropins in women with thin endometrium $(<7 \mathrm{~mm})$ after clomiphene in intrauterine insemination cycles: a prospective study. J Hum Reprod Sci 11(1): 3439. 
40. Seyedoshohadaei F, Zandvakily F, Shahgeibi S (2012) Comparison of the effectiveness of clomiphene citrate, tamoxifen and letrozole in ovulation induction in infertility due to isolated unovulation. Iran J Reprod Med 10(6): 531-536.

41. Evron S, Navot D, Laufer N, Diamant YZ (1983) Induction of ovulation with combined human gonadotropins and dexamethasone in women with polycystic ovarian disease. Fertil Steril 40(2): 183-186.

42. Højlund K, Dorte G, Nicoline RA, Jesper BB, Jonas TT, et al. (2008) Impaired insulin-stimulated phosphorylation of Akt and AS160 in skeletal muscle of women with polycystic ovary syndrome is reversed by pioglitazone treatment. Diabetes 57(2): 357-366.

43. Tang $\mathrm{T}$ (2012) Insulin-sensitising drugs (metformin, rosiglitazone, pioglitazone, D-chiro-inositol) for women with polycystic ovary syndrome, oligo amenorrhoea and subfertility. Cochrane Database of Systematic Reviews (5).

44. Legro RS, Robert GB, Michael PD, Christos C, William DS, et al. (2014) Letrozole versus clomiphene for infertility in the polycystic ovary syndrome. N Engl J Med 371(2): 119-129.

45. Elnashar A, Emad A, Mahmod F, Magdy S (2006) Clomiphene citrate and dexamethazone in treatment of clomiphene citrate-resistant polycystic ovary syndrome: a prospective placebo-controlled study. Human Reprod 21(7): 1805-1808.

46. Faslul Haq M (2012) Effect of 'Dawa-ul-Husk'on Human Seminal Fluid Anomalies.

47. Maharjan R, Nagar PS, Nampoothiri L (2010) Effect of Aloe barbadensis Mill. formulation on Letrozole induced polycystic ovarian syndrome rat model. J Ayurveda Integr Med 1(4): 273-279.

48. Jitendra PA, Pravin TA (2012) Prospective use of Tephrosia purpurea in remedial treatment of PCOS: study in Wistar rat. ISCA J Biological Sci 1: 1-6.

49. Jadhav M, Menon S, Shailajan S (2013) In vivo evaluation of Mimosa pudica linn. In the management of polycystic ovary using rat model.

50. Jain R, Kachhwaha S, Kothari S (2012) Phytochemistry, pharmacology, and biotechnology of with ania somnifera and Withania coagulans: A review. Journal of Medicinal Plants Research 6(41): 5388-5399.

51. Mohd J (2012) Pharmacological scientific evidence for the promise of Tribulus terrestris. International Research Journal of Pharmacy 3(5): 403-406.

52. Hannan J, Liaquat A, Junaida K, Masfida A, Peter RF, et al. (2012) Antihyperglycaemic activity of Asparagus racemosus roots is partly mediated by inhibition of carbohydrate digestion and absorption, and enhancement of cellular insulin action. Br J Nutr 107(9): 1316-1323.

53. Pachiappan S, Suganeswari M, Poorana PS, Gayathiri M (2017) Medicinal plants for polycystic ovary syndrome: A review of phytomedicine research. International Journal of Herbal Medicine 5(2): 78-80.

54. Jungbauer A, Medjakovic S (2014) Phytoestrogens and the metabolic syndrome. J Steroid Biochem Mol Biol 139: 277-289.

55. Siriwardene SD, Karunathilaka LPA, Kodituwakku ND, Karunarathne YAUD (2010) Clinical efficacy of Ayurveda treatment regimen on
Subfertility with poly cystic ovarian syndrome (PCOS). Ayu 31(1): 2427.

56. Sawant A, Patil S, Shah S (2017) Review on PCOD/PCOS \& its treatment in different medicinal systems-allopathy, ayurveda, homeopathy. Sci Jurno 1(1): 1-16.

57. Sharma P, Sharma U, Sharma S () An Effort to Understand Pcos In Ayurveda Context. Infertility 40: 17.

58. Pole S (2006) Ayurvedic medicine: The principles of traditional practice. In: ( $1^{\text {st }}$ edn), Elsevier Health Sciences.

59. Bhatted S, Shukla VD, Anup T, Bhatt NN (2011) A study on Vasantika Vamana (therapeutic emesis in spring season)-A preventive measure for diseases of Kapha origin. Ayu 32(2): 181-186.

60. Verma, A (2015) Management of PCOS: A psychosomatic disorder by yoga practice. Interna J Innovat Res Develop 4(1): 1.

61. Merekar AN, Pattan S, Dighe N (2009) Female infertility and its treatment by alternative medicine: a review. Journal of Chemical and Pharmaceutical Research 1(1): 148-162.

62. Sangeeta S, Management of PCOS Through Shodhana (Bio-Purification) A Panchkarma Modality-A Single Case Study.

63. Ruta K (2014) Contemporary and traditional Perspectives of Polycystic Ovarian Syndrome (PCOS): A critical review. IOSR J Dent Med Sci 13: 89-98.

64. Chaganti S, Prasad B (2015) Analysis of Virechana karma with Danti avaleha: A retrospective study. J Ayurveda Integr Med 6(4): 300.

65. Khandelwal R, Dipti SN, IJAMSI International Journal of Ayurveda \& Medical Sciences.

66. Shinde P (2016) Basti In Female Infertility (Vandhyatva): A Critical Analysis. Pharma Science Monitor 7(3).

67. Khot BM (2013) Clinical efficacy of Ayurveda treatment on polycystic ovarian syndrome. J Pharm 3: 21-25.

68. Ammon H, Kemper FJDMW (1982) Ayurveda: 3000 years of Indian traditional medicine. Med Welt 33(4): 148.

69. Sawant A, Patil S, Shah S (2017) Review on PCOD/PCOS \& its treatment in different medicinal systems-allopathy, ayurveda, homeopathy. Sci Jurno 1(1): 1-16.

70. Tewari PV (1996) Ayurveda Prasuti Tantra Evam Stri Roga, Stri Roga, Chaukambha Orientale. Varanasi 169: 192.

71. Sharma PV (1981) Charaka Samhita (English Translation) Chaukambha Orientalia. Varanasi.

72. Srikantha Mruthi KR (2001) Sushruta Samhita (English Translation) Chaukambha Orientale. Varanasi, pp. 170-173.

73. Dayani Siriwardene SA, Karunathilaka LP, Kodituwakku ND, Karunarathne YA (2010) Clinical efficacy of Ayurveda treatment regimen on Subfertility with Poly Cystic Ovarian Syndrome (PCOS). Ayu 31(1): 24-27. 


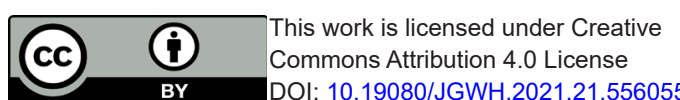
Commons Attribution 4.0 License
DOI: $10.19080 / J G W H .2021 .21 .556055$

\section{Your next submission with Juniper Publishers will reach you the below assets}

- Quality Editorial service

- Swift Peer Review

- Reprints availability

- E-prints Service

- Manuscript Podcast for convenient understanding

- Global attainment for your research

- Manuscript accessibility in different formats

( Pdf, E-pub, Full Tsext, Audio)

- Unceasing customer service

Track the below URL for one-step submission https://juniperpublishers.com/online-submission.php 